Knibbe, J.J., Friele, R.D. The use of logs to assess exposure to manual handling of patients, illustrated in an intervention study in home care nursing. International Journal of Industrial

\begin{tabular}{|l|l|}
\hline $\begin{array}{l}\text { Postprint } \\
\text { Version }\end{array}$ & 1.0 \\
\hline $\begin{array}{l}\text { Journal website } \\
\text { Pubmed link }\end{array}$ & $\underline{\text { http://dx.doi.org/10.1016/S0169-8141(99)00010-4 }}$ \\
\hline DOI & $10.1016 / \mathrm{S} 0169-8141(99) 00010-4$ \\
\hline
\end{tabular}

This is a NIVEL certified Post Print, more info at http://www.nivel.eu

\title{
The use of logs to assess exposure to manual handling of patients, illustrated in an intervention study in home care nursing
}

\section{J. J. KNIBBE’AND R. D. FRIELE}

NIVEL, Netherlands Institute of Primary Health Care, PO BOX 1568, 3500 BN UTRECHT, Netherlands

\section{ABstract}

This article approaches the option of logging lifting activities by nurses in patient care. Practical problems in nursing limit the use of direct observation and measurements to assess exposure to lifting in real life settings. Indications were found that logs registering the frequency of manual handling could be an option in nursing. The development of a $\log$ is accounted for and its use during an intervention, introducing 40 patient hoists in home care, is described. The exposure to manual handling was reduced significantly in the intervention group (average number of patient transfers per nurse/week (ptn/w) 35-21). The control group remained stable (ptn/w 24-24). The reduction of exposure was only partly due to the hoists substituting manual transfers, suggesting the presence of an elimination effect. Possible explanations indicating that the hoists were partly responsible for this are:

1. The patients' relatives could now perform the transfers with the hoist;

2. Hoists combine several manual transfers into one mechanical transfer;

3. Hoists require only one operator for manual transfers that require two nurses.

The $\log$ pointed to unpredicted elimination effects in addition to the substitution effects, and provided detailed information for evaluating the intervention.

\section{Relevance to industry}

Assessment of exposure to manual handling, using a frequency-oriented log, appears to provide relevant information for designing back pain prevention policies in nursing. Insight is given into the effects of an intervention using hoists. With some adaptations, the log could monitor ergonomic policies in nursing practice on a routine basis. 
Knibbe, J.J., Friele, R.D. The use of logs to assess exposure to manual handling of patients, illustrated in an intervention study in home care nursing. International Journal of Industrial Ergonomics: 1999, 24(4), 445-454

\section{INTRODUCTION}

Nurses are at risk of developing occupational back pain. Within the profession, those working in home-care represent a high risk group (Knibbe and Friele, 1996). Manual handling (lifting, etc.) of patients is considered a major risk factor for the high back pain prevalence ( Garg et al., 1991a, Garg et al., 1991b; Smedley et al., 1995).

There is only limited information on the exact nature and level of exposure of nurses to manual handling. The assessment of exposure in relation to occupational back pain is important (Burdorf and Van Riel, 1996). This is especially true of the assessment of the effect of interventions. A change in back pain prevalence can only be attributed to an intervention if it is parallelled by a change in exposure.

Current information on exposure of nurses to manual handling is mostly based on recall in questionnaires (Videman and Videman; Harber andHarber; Mandel and Lohman, 1987; Estryn-Behar et al., 1990; Smedley et al., 1995; Wigaeus Hjelm et al., 1995). The results indicate that the occurrence of back pain is related to an increased physical workload and, more particularly, the lifting frequency. Nevertheless Burdorf (1993) noted that this type of recall of exposure can lead to considerable misclassification, which can bias an effect estimate in interventions in the direction of the null value.

Others have used direct observation (Harber et al., 1988b; Engels and Engels; Van der Beek et al., 1995; Lusted et al., 1996), but the information on the exact frequencies of transfers is limited. The results of Van der Beek et al. (1995) are worth mentioning. They observed a group of five nurses and three other occupational groups. They assessed the sources of variance of exposure to non-neutral trunk postures. The within-worker-variance was the most important source of variability. There was also a large variation in the tasks performed by the nurses. They recommend the use of more measurements per nurse to obtain more precise estimates and the use of a task-oriented measurement strategy.

The methods these studies employed have important limitations. On the other hand, the direct measurement of exposure in actual nursing practice presents substantial difficulties. Apart from the complex, labour intensive, biomechanical analyses (Garg and Garg; De Looze et al., 1994), the considerable interference with the privacy and continuity of patient care makes an on-site assessment very difficult. As a result, often only a few nurses can be studied, during relatively short periods of time.

In this article, the development of an exposure assessment instrument for patient handling (a seven-day self-administered log called the 'Lift Counter'(LC)) is described. Secondly, the results from a controlled preventive intervention in home care nursing are presented, demonstrating the use, limitations and some of the measurement characteristics of the log.

\subsection{Frequency of manual handling}

Jensen (1990) reviewed six studies that were consistent in finding higher back pain prevalence rates among nurses who lifted patients more frequently. The overall back pain prevalence rate of nurses handling patients frequently was 3.7 times that of infrequent patient handlers. These results are in line with the results of other studies ( Estryn-Behar et al., 1990; Smedley et al., 1995; Wigaeus Hjelm et al., 1995) and point to the basic idea that every manual patient transfer could present a nominal risk for the occurrence of back pain (Jensen, 1990). This is supported by the conclusions from biomechanical studies, reporting that the magnitude of the load is such that acceptable biomechanical limits for the back load are exceeded during various manual patient transfers ( Garg et al., 1991a, Garg et al., 1991b; Winkelmolen et al., 1994). The duration of the transfers is short, lasting a few seconds. These findings suggest a tempting solution for the assessment of exposure due to patient handling in real life situations.

In this line of thought, the frequency of lifting actions to which nurses are exposed may be more important for the risk of developing back pain than the exact load per transfer or the duration of the transfer. The reverse of this suggests that a reduction in the frequency of these transfers would result in a reduction of back pain prevalence. A valid and reliable 
Knibbe, J.J., Friele, R.D. The use of logs to assess exposure to manual handling of patients, illustrated in an intervention study in home care nursing. International Journal of Industrial Ergonomics: 1999, 24(4), 445-454

record of the frequency of the transfers nurses perform might provide a basis for assessing exposure to manual handling.

The 'Lift Counter' (LC) was developed based on this principle of counting lifting actions. It was decided to use a self-administered log, to avoid problems with recall and patients' privacy.

\subsection{Logs}

There has been a considerable debate about the reliability and validity of using selfadministered logs or diaries to assess exposure to physical loads (Burdorf, 1992). The research results are partly contradictory. Positive findings come from two home care studies. Kerkstra and De Wit (1987) found self-registration to be a reliable method of assessing the frequency of nursing activities, including patient handling, when compared to direct observation. Arts et al. (1996) report an agreement of $94-98 \%$ between observation and self registration among home helps.

Wiktorin et al. (1993) analyzed the validity of self-reported exposure to manual materials handling by comparisons with direct observation and measurement. They found an improved relation with an increase of the weight of the load and when frequency was registered as opposed to duration. Apparently it is easier to discriminate between being exposed or not exposed to material handling, especially with heavier loads, than to quantify the exposure in more detail. This is line with the findings of Kerkstra and De Wit (1987) and Arts et al. (1996), who also found the association weaker with more detailed activities. Wiktorin et al. (1993) therefore suggest that self-reported exposure of manual handling of loads over $5 \mathrm{~kg}$ in high risk occupations, can be acceptable. This situation applies to home care nursing (Knibbe and Friele, 1996).

These findings seem to contradict the conclusions of Van der Beek et al. (1994) and Burdorf and Laan (1991). Since they found a poor agreement between self-reporting and direct observation, they discourage the use of diaries and questionnaires. Nevertheless, two essential differences need to be mentioned. First of all, it seems that the highest degree of reliability is found in studies focusing on the frequency of occurrence of activities as opposed to duration. In related fields of research, like dietary assessment, the use of food frequency questionnaires and 7-day food records also yields satisfactory results ( Jain et al., 1996). Secondly, the nature of the description of the activities differs. An important common characteristic of the home care studies is that workers were registering meaningful activities that were closely related to their working routines (like lifting someone out of bed) as opposed to biomechanically important but abstract entities like body position (i.e. flexion of the trunk) such as Van der Beek et al. (1994) and others have used.

To conclude it seems reasonable to assume that if the LC refers to meaningful activities performed by the nurse; to heavy manual handling in a high risk profession and concentrates on registering frequencies, it can be seen as a valid tool in assessing exposure to handling patients in home care. An additional argument for counting lifting actions in our case was the fact that our intervention focused exactly on this issue, i.e.: reducing the frequency of manual handling by using hoists. This direct relationship with the nature of an intervention can be an advantage (Kilbom, 1994).

Having made the decision to use a log, it is important to consider possible sources of bias in reporting exposure. Wiktorin et al. (1993) and Viikari-Juntura et al. (1996) found that low back complaints caused a differential bias in reporting exposure: subjects without low back complaints seemed to underreport manual handling. Van der Beek et al. (1994) also stressed the need to identify bias due to an elevated level of perceived exertion during manual handling.

\subsection{Research question}

The basic question to be answered is: what changes does a self-administered log (the LC) detect in the nature and amount of exposure to patient handling, induced by the introduction of patient lifting hoists in home care nursing. The hypothesis is that the introduction of hoists 
Knibbe, J.J., Friele, R.D. The use of logs to assess exposure to manual handling of patients, illustrated in an intervention study in home care nursing. International Journal of Industrial Ergonomics: 1999, 24(4), 445-454

will lead to a significant reduction in exposure to manual handling and back pain prevalence in the intervention group, while there will be no significant changes in these aspects in the control group. The issue of bias mentioned above will be studied in the results of the log.

\section{METHOD}

\subsection{Development of the LC}

Efforts were made to label activities closely linked to daily nursing routines. A qualitative inventory $(n=131)$ resulted in 11 categories of nursing activity relating to patient transfers. This was developed into a personal $\log$, which was pre-tested $(n=118)$. In the final LC, the employment rate (hours/week) and the type of shift had to be indicated. The following variables had to be registered for every transfer: patient number; the type of transfer (11 fixed options); the amount of patient cooperation ( 3 options); the number of persons involved; assistance from informal care $(\mathrm{Y} / \mathrm{N})$; the use of equipment (none, height adjustable beds, small assistive aids and patient hoists) and finally an estimate of the patient's weight. The amount of patient cooperation was divided into three levels. The first one ('none/hardly any') refers to passive patients. 'Limited' was reserved for patients able to assist, but unable to perform any action themselves. 'Good' cooperation referred to patients able to perform part of the movement themselves.

\subsection{The intervention}

Forty patient hoists were introduced in the study period of one year. They were intended to reduce or eliminate manual transfers from bed, (wheel) chair to chair/toilet or vice versa. The intervention also involved training, the use of ergonomic assessment forms and the introduction of 12 specially trained 'lifting coordinators'. The control group continued their normal routines, with the two hoists already available at their disposal.

\subsection{Studying the intervention}

All home care nurses $(n=378)$ working in the city of Rotterdam were invited to participate. They provide professional nursing care around the clock, seven days a week, for patients living at home. The 20 teams within the organisation were assigned to what was defined as either the control (12 teams, $n=239$ ) or the intervention group ( 8 teams, $n=139)$. The restrictions on assignment were that any interaction or transition of staff between control and intervention groups had to be avoided and time for training had to be available. The remaining selection was made at random.

The LC was used to monitor exposure to patient handling for seven consecutive days, before the start of the intervention and one year after.

The nurses were also surveyed, as part of the total group of nurses in this home care organisation. The survey disclosed general information (age, working experience, working hours) and health characteristics like back pain prevalence (Knibbe and Friele, 1996). At baseline this survey also included a Borg-scale ( Owen and Garg, 1991, Knibbe and Friele, 1993) to assess the perceived exertion for the LC categories and 4 statements on feelings of physical exhaustion ( 7 point scale ranging from 'never' to 'always').

\subsection{Data analysis}

The data was analyzed by means of SPSS PC+5.0 (Norusis, 1992). Differences in nominal data were tested with McNemar's statistic (dependent groups) and Chi-square test (independent). Differences in sets of ordinal data were tested with Wilcoxon's statistic (dependent sets) and Mann-Whitney's test (independent sets). The T-test was used for interval data, assuming a normal data distribution (Kolmogorov-Smirnov statistic). Linear regression was used to study the relationships between predictor variables and the total number of transfers. $P$-values below 0.05 were considered significant. 
Knibbe, J.J., Friele, R.D. The use of logs to assess exposure to manual handling of patients, illustrated in an intervention study in home care nursing. International Journal of Industrial Ergonomics: 1999, 24(4), 445-454

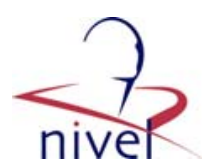

\section{RESULTS}

\subsection{Population}

The response rates to the surveys were $94 \%(n=355)$ at baseline and $86 \%(n=298)$ post intervention. The main survey results are reported elsewhere and used here whenever relevant (Knibbe and Friele, 1996).

The LC was distributed among a group of 108 randomly selected nurses, who received 30 min personal instruction, after which telephone help was available. At baseline 104 LC's were collected, indicating a response rate of $96 \%$. The same LC-group $(n=104)$ was asked to participate again, post intervention. Due to the drop-out rate (18 nurses left the service, 3 were absent due to pregnancy) other nurses were instructed, resulting in a total number of 117 LC's (overall response rate: $70 \%$ ). One LC was removed due to missing data, leaving a total of 116 LC's for analysis.

At baseline, the nurses working with the LC ( $n=104$, average age $34.6 \mathrm{yr}(\mathrm{SD}=8.8 ; 21-58$, average working experience $13.3 \mathrm{yr}(\mathrm{SD}=8.1 ; 1-36)$ worked on average $26.8 \mathrm{~h} /$ week $(\mathrm{SD}=11.7 ; 2-49)$ mostly in day-shifts $(73.3 \%)$. There were no significant differences with the total group surveyed on both occasions or with the LC-group at post intervention ( $T$-test and Chi-square, $p<.05$ ).

\subsection{Pre intervention}

The surveys reported a 12-month back pain prevalence of 67\% (Knibbe and Friele, 1996). The prevalence differed significantly between the intervention group $(n=132)(74 \%)$ and the control group ( $n=223)(62 \%)$ (Chi-square, $p<0.05)$.

At the baseline LC's $(n=104)$ a total of 3020 transfers was recorded. The majority $(80.1 \%)$ were carried out alone by the nurses, that is, without assistance from anyone else. Most of the remaining transfers $(19.1 \%)$ were by nurses, assisted by a second person, either a colleague or informal care.

The average patient weight was $68.2 \mathrm{~kg}(\mathrm{SD}=13.4,25-150)$. Four patients weighed over $100 \mathrm{~kg}$. In $32.2 \%$ of the transfers the patient was unable to assist, in $45.3 \%$ there was limited assistance and in $22.5 \%$ the patient's assistance was rated as 'good'. In more than half $(60.8 \%)$ of the transfers no assistive equipment was used. The most frequently used aid was the adjustable height bed (32.6\%). In $4.8 \%$ of the instances, smaller aids like turntables were chosen. Patient hoists were used in $7.7 \%$ of the transfers. Sometimes there was simultaneous use of different equipment (5.9\%).

The results of aggregating the data for all seven days to the level of the nurses are presented in Table 1. The average frequency of the 11 transfer categories per nurse per week are indicated. It is clear that the nurses performed a diversity of transfers. The hoists used in the intervention provide solutions for transfer categories $1-4$ and 11 . As this amounts to $30.1 \%$ of the total number of transfers, the intervention focused on roughly one third of the exposure to manual patient handling. For two major categories (5 and 6 (transfers within the limits of a bed) $(31.6 \%)$ ) the hoists provided no adequate solution as they are not designed for this purpose.

\section{[TABLE 1]}

At baseline, the intervention group $(n=50)$ performed more transfers than the control group $(n=54)$ did (Mann-Whitney, $p=0.0025)$. Significant differences occurred for the transfer from bed $(-\rangle$ (wheel) chair $(p=0.009)$ and both types of 'in-bed-transfers' $(p=0.0008$ and $p=0.012$ ).

Linear regression on the total number of transfers from the combination of control and intervention group $(n=104)$ indicated no significant association with the variables age, working experience, presence of back pain in the past 12 months or back pain in the past 7 days, employment rate, the average perceived exertion during the 11 transfers and the average rating of general physical exhaustion. 
Knibbe, J.J., Friele, R.D. The use of logs to assess exposure to manual handling of patients, illustrated in an intervention study in home care nursing. International Journal of Industrial Ergonomics: 1999, 24(4), 445-454

\subsection{Post intervention}

The 12-month back pain prevalence in the intervention group was reduced significantly to $64 \%$, at post intervention (McNemar, $p<0.05$ ), while the control group remained stable $(66 \%)$. The difference between both groups is not significant (Chi-square, $p<0.05$ ).

The aggregated results from the $116 \mathrm{LC}$ 's (2631 transfers) indicate a significant reduction for categories 3-5, 8 and the total number of transfers in the intervention group, while the control group showed a significant reduction on category 10 (Table 1). The differences in number of transfers found at baseline between intervention and control group disappeared, while there was a difference in category 7 (Mann-Whitney, $p=0.0007$ ). In summary, an overall reduction of the number of transfers is visible in the intervention group from 35 to 21 transfers per nurse/week, while the control group remained stable (24 on both occasions).

As the intervention focused on the introduction of hoists, the frequency with which they are used is an important indicator of the impact of the intervention. As stated above, it appeared that the hoists could provide solutions for about one third of the total number of transfers. Table 2 shows the average of the total number of transfers per nurse per week, the average number of transfers for which a hoist can be used ('hoist potential') and the average number of remaining transfers ('non-hoist transfers'). For the intervention group a reduction in the total number of transfers is visible in both groups of transfers (hoist and non-hoist transfers) of approximately $50 \%$ and $35 \%$. The frequency with which hoists are used increased slightly ( 2.9 versus 3.5 ), with a relative increase of hoist use from $25 \%$ to $57 \%$ of the number of transfers that could potentially be performed with a hoist. The control group remained stable both in the actual number of hoist transfers (1.6 versus 1.9$)$ and in relative use $(27.7 \%$ and $25.7 \%$ of the hoist potential)

\section{[TABLE 2]}

In order to monitor the intervention it is important to assess the type of patient the hoists are used for. At baseline in $24.6 \%$ of the transfers for which a hoist could be used, it was used (Table 2). These were all passive patients. However, one third (32.2\%) of all transfers involved passive patients, indicating that most, but not all of the passive patients were lifted with a hoist. After the intervention, all passive patients were lifted with hoists. In addition to this, hoists were also used for $54 \%$ of the transfers of patients with limited cooperation.

\section{DISCUSSION}

\subsection{Method}

Apart from some support from the literature, four other aspects may have improved the reliability of the LC in this particular study. The personal instruction was aimed at motivating the nurses and avoiding misclassification. The $\mathrm{LC}$ was used right after each patient visit. This short recall and the fact that the nurses always recorded their activities at that time might have improved compliance. Finally the fact that transfers during a care process have a logical sequence could have prevented errors. For example, it is unlikely that the only transfer was from wheelchair to toilet, if the patient was in bed on arrival of the nurse. Although the indications seem positive, further research into reliability and validity is required, especially since some of the indications are very specific to the setting studied.

The nurses had little comment on the log and its use. As the two categories of 'within-bed' transfers seem to overlap, they will be combined into one. For monitoring purposes, more categories could be combined, whenever the preventive solution is similar; for example, transfers related to hoists and transfers related to sliding sheets. Furthermore, replacing the 7day record by a 24-h monitoring of physical exposure provides the option of linking monitoring to the routine $24-\mathrm{h}$ record already kept in nursing for organizational and financial purposes (Cardona et al., 1997). Because such a 'lift-count-day' may limit the identification 
Knibbe, J.J., Friele, R.D. The use of logs to assess exposure to manual handling of patients, illustrated in an intervention study in home care nursing. International Journal of Industrial Ergonomics: 1999, 24(4), 445-454

of the effects mentioned above, different versions are currently being studied in different health care sectors.

\subsection{Intervention}

It is clear that the selection of intervention and control group did not result in similar base line values for exposure to manual handling or for back pain prevalence; the intervention group was more exposed and had a higher back pain prevalence. Selection has apparently taken place. We consider this was inevitable, as random selection would have caused interference between the groups during the intervention.

The differences between both groups have disappeared post intervention and the changes were in the direction expected: less exposure to manual handling and a lower back pain prevalence in the intervention group and a fairly stable control group. The change in back pain prevalence is minimal. There was, however, a remarkably large reduction in the overall frequency of transfers in the intervention group. This reduction could, as is evident from the results, contrary to our expectations, be traced only partially to the substitution of transfers with a hoist for manual transfers. Four potential reasons for this elimination effect and the likelihood of an external effect acting only on the intervention group will now be explored. The nurses said that a considerable number of transfers were totally eliminated, because relatives were able to care for the patient with the use of the hoist, without the presence of the nurse. This elimination effect was demonstrated before in home care when the introduction of aids enabled patients to put their pressure stockings on by themselves (Friele and Kerssens, 1995). This previously strenuous physical activity was often the only reason for professional help and the need for help disappeared after the introduction of the aid. It is not possible to estimate the size of this elimination effect, as the LC specified nurse data, whereas individual patients could not be recognized.

A second possibility is that manual transfers requiring two nurses were replaced by one nurse using a hoist. This eliminates one manual transfer and substitutes a second one in the LC data. Limited support for this effect can be found as the intervention group performed $0.9 \%$ transfers with a colleague, while this was $2.0 \%$ beforehand. This effect could be much stronger in hospital care, where sharing transfers with a colleague ranges from $23 \%$ to $69 \%$ of all transfers (Lusted et al., 1996). The introduction of hoists there could have a profound influence on working routines and the effect on exposure of the nurses could also be larger than expected on the basis of substitution alone.

A third and probably larger elimination effect results from replacing several manual transfers by one transfer with a hoist. For example, a hoist needs one transfer to go from lying in bed to sitting on a toilet. The manual alternative often results in one transfer from lying to sitting, a second one from bed to wheelchair and a third one from wheelchair to toilet. Support can be found in the significant reduction that took place in two of these three categories (Table 1), while the transfer from bed to toilet remained stable.

Nurses emphasized a fourth unpredicted effect, when stating that the hoists eliminated a substantial number of transfers 'within' bed. For example: getting a patient clean and dressed in bed requires several 'within' bed transfers in a row. With some hoists, it was possible to do this while the patient was supported in a semi-standing position out of bed. This would eliminate several 'within' bed transfers and explain the reduction visible in Table 1.

As nurses in home care teams often routinely attend to the same patients daily (once or twice), the combination of the four effects mentioned above may result from several nurses dealing with the same patient. This can account for a large overall reduction effect. It is impossible to calculate the size of these effects as individual patients could not be identified in the LC data.

As stated above, the possibility of an external influence resulting in the reduction needs to be explored. The control group demonstrated a remarkably stable exposure pattern in time and type of transfer. This, in addition to the absence of (external) organizational changes 
Knibbe, J.J., Friele, R.D. The use of logs to assess exposure to manual handling of patients, illustrated in an intervention study in home care nursing. International Journal of Industrial Ergonomics: 1999, 24(4), 445-454

limited to the intervention group, increased the likelihood that the above effects are at least partially responsible for the unexpectedly large overall reduction of the number of transfers.

The option of a 'Hawthorne-effect' remains: the nurses may have had a strong desire to make the intervention 'work' by reporting a frequent hoist use. Although it cannot be ruled out, it is not supported by the relatively small increase in the frequency of hoist use they report, as opposed to the large overall reduction in transfers.

With respect to possible bias, the absence of a relation between the presence of back pain, a high level of perceived exertion and the reported exposure is not conclusive. It cannot be excluded that nurses with back pain refrained from heavy manual handling. This would counteract the bias that Wiktorin et al. (1993) and Van der Beek et al. (1994) refer to, namely that workers with back pain tend to overreport manual handling. The presence of the former selection effect is likely in our study as $16 \%$ of the nurses with back pain in the prior three months stated that they had exchanged patients with colleagues for reasons of back pain ( Knibbe and Friele, 1996).

\section{CONCLUSION}

The detailed assessment of patient transfers enabled a more thorough evaluation of the impact of introducing hoists and pointed to unexpected effects. If the LC had not been used, it might have reinforced the theory of hoists mainly substituting manual handling, while they also seem to eliminate handling, and the theory that hoists provide a solution for the majority of transfers, while in reality they only focus on one third of the total number of manual transfers carried out in home care. The results also demonstrated that although all passive patients were lifted with a hoist after the intervention, a lot of patients capable of only limited assistance were still lifted manually. This can be relevant information when monitoring an intervention.

In conclusion, the LC enabled us to gain insight in the changes in exposure to manual handling of patients resulting from the introduction of lifting hoists. The use of a log like the LC deserves attention in this sector, particularly when direct observation and measurements are not possible. The results underline the importance of assessing exposure in creating more understanding of the necessary direction, effects and side-effects of a preventive intervention for manual handling.

\section{REFERENCES}

Arts, S., Kersten, H. and Kerkstra, A., 1996. The daily practice in home help services in the Netherlands : instrument development. Health and Social Care in the Community 4, pp. 280-289.

Beek, A.J. Van der, Braam, I.T.J., Douwes, M., Bongers, P.M., Frings-Dresen, M.H.W., Verbeek, J.H.A.M., Luyts, S., 1994. Validity of a diary estimating exposure to tasks, activities, and postures of the trunk. International Archives of Occupational Environment and Health 66, 173-178.

Beek, A.J. Van der, Kuiper, J.I., Dawson, M., Burdorf, A., Bongers, P.M. and Frings-Dresen, M.H.W., 1995. Sources of variance in exposure to nonneutral trunk postures in varying work situations. Scandinavian Journal of Work, Environment and Health, 21, 215-222..

Burdorf, A., 1992. Sources of variance in exposure to postural load on the back in occupational groups. Scandinavian Journal of Work, Environment and Health 18, pp. 361367.

Burdorf, A., 1993. Bias in risk estimates from variability of exposure to postural load on the back in occupational groups. Scandinavian Journal of Work, Environment and Health 19, pp. 50-54.

Burdorf, A. and Laan, J., 1991. Comparison of three methods for the assessment of postural load on the back. Scandinavian Journal of Work, Environment and Health 17, pp. 425-429.

Burdorf, A. and Van Riel, M., 1996. Design of strategies to assess lumbar posture during work. International Journal of Industrial Ergonomics 18, pp. 239-249. 
Knibbe, J.J., Friele, R.D. The use of logs to assess exposure to manual handling of patients, illustrated in an intervention study in home care nursing. International Journal of Industrial Ergonomics: 1999, 24(4), 445-454

Cardona, P., Tappen, R.M., Terrill, M., Acosta, M. and Eusebe, M.I., 1997. Nursing staff time allocation in long-term care. JONA 27, pp. 28-36.

Engels, J.A., Gulden, J.W.J., Senden, T.F., Hertog, C.A.W.M., Kolk, J.J. and Binkhorst, R.A., 1994. Physical work load and its assessment among the nursing staff in nursing homes. Journal of Occupational Medicine 36, pp. 338-345.

Engels, J.A., Landeweerd, J.A. and Kant, Y., 1994. An OWAS-based analysis of nurses' working postures. Ergonomics 37, pp. 909-919.

Estryn-Behar, M., Kaminski, M., Peigne, E., Maillard, M.F., Pelletier, A., Berthier, C., Delaporte, M.F., Paoli, M.C. and Leroux, J.M., 1990. Strenuous working conditions and musculo-skeletal disorders among female hospital workers. International Archives of Occupational Environment and Health 62, pp. 47-57.

Friele, R.D., Kerssens, J.J., 1995. Techniek in de thuiszorg, een evaluatie van het stimuleringsprogramma thuiszorgtechnologie, (summary in English), NIVEL, Utrecht 158 pp..

Garg, A., Owen, B., Beller, D. and Banaag, J., 1991. A biomechanical and ergonomic evaluation of patient transferring tasks: bed to wheelchair and wheelchair to bed. Ergonomics 34, pp. 289-312.

Garg, A., Owen, B.D., Beller, D. and Banaag, J., 1991. A biomechanical and ergonomic evaluation of patient transferring tasks: : wheelchair to shower chair and shower chair to wheelchair. Ergonomics 34, pp. 407-419.

Harber, P., Billet, E., Shimozaki, S. and Vojtecky, M., 1988. Occupational back pain of nurses: : special problems and prevention. Applied Ergonomics 19, pp. 219-224.

Harber, P., Billet, E., Vojtecky, M., Rosenthal, E., Shimozaki, S. and Horan, M., 1988. Nurses' beliefs about cause and effect of occupational back pain. Journal of Occupational Medicine 30, pp. 797-800.

Harber, P., Shimozaki, S., Gardner, G., Billet, E., Vojtecky, M. and Kanim, L., 1987. Importance of non-patient transfer activities in nursing related back pain. Journal of Occupational Medicine 29, pp. 971-974.

Jain, M., Howe, G.R. and Rohan, T., 1996. Dietary assessment in epidemiology: comparison on food frequency and a diet history questionnaire with a 7-day food record. American Journal of Epidemiology 143, pp. 953-960. Jensen, R.C., 1990. Back injuries among nursing personnel related to exposure. Applied Occupational and Environmental Hygiene 5, pp. 38-45.

Kerkstra, A., De Wit, A.M.G.J., 1987. Het werk van wijkverpleegkundigen en wijkziekenverzorgenden: instrumentontwikkeling (in Dutch). NIVEL, Utrecht, 217 pp..

Kilbom, A., 1994. Assessment of physical exposure in relation to work-related musculoskeletal disorders- what information can be obtained from systematic observations?. Scandinavian Journal of Work, Environment and Health 20 Special Issue, pp. 30-45.

Knibbe, J.J., Friele, R.D., 1993, Back pain and patient lifting in nurses working in home care in: Hagberg, M., Hofmann, F., Stossel, U., Westlander, G. (Eds.), Occupational Health for Health Care Workers. Ecomed, Landsberg, pp 312-314..

Knibbe, J.J. and Friele, R.D., 1996. Prevalence of back pain and characteristics of the physical workload of community nurses. Ergonomics 39, pp. 186-198.

Looze, M.P. de, Zinzen, E., Caboor, D., Heyblom, P., Bree, E.van, Roy, P. van, Toussaint, H.M., Clarijs, J.P., 1994. Effect of individually chosen bed-height adjustments on the lowback stress of nurses. Scandinavian Journal of Work, Environment and Health 20, 427434..

Lusted, M.J., Carrasco, C.L., Mandryk, J.A. and Healy, S., 1996. Self reported symptoms in the neck and upper limbs of nurses. Applied Ergonomics 27, pp. 381-387.

Mandel, J.H. and Lohman, W., 1987. Low back pain in nurses: : the relative importance of medical history, work factors, exercise and demographics. Research in Nursing and Health 10, pp. 165-170.

Norusis, M.J., 1992. SPSS /PC+ User's guide, version 5.0., SPSS Inc., Chicago..

Owen, B.D. and Garg, A., 1991. Reducing risk for back pain in nursing personnel. AAOHN Journal 39, pp. 24-33. 
Knibbe, J.J., Friele, R.D. The use of logs to assess exposure to manual handling of patients, illustrated in an intervention study in home care nursing. International Journal of Industrial Ergonomics: 1999, 24(4), 445-454

Smedley, J., Egger, P., Cooper, C. and Coggon, D., 1995. Manual handling acitivities and the risk of low back pain in nurses. Occupational and Environmental Medicine 52, pp. 160163.

Videman, T., Nurminen, T., Tola, S., Kuorinka, I., Vanharanta, H. and Troup, J.D.G., 1984. Low-back pain in nurses and some loading factors of work. Spine 9, pp. 400-404.

Videman, T., Rauhala, H., Asp, S., Lindstrom, K., Cedercreutz, G., Kamppi, M., Tola, S. and Troup, J.D.G., 1989. Patient-handling skill, back injuries, and back pain an intervention study in nursing. Spine 14, pp. 148-156.

Viikari-Juntura, E., Rauas, S., Martikainen, R., Kuosma, E., Riihimaki, H., Takala, E.P. and Saarenmaa, K., 1996. Validity of self-reported physical work load in epidemiological studies on musculoskeletal disorders. Scandinavian Journal of Work, Environment and Health 22, pp. 251-259.

Wigaeus Hjelm, E., Engkvist, J.L., Andersson, Y., Hagberg, M., Menckel, E., Persson, P.G., Ekenvall, L., 1995. Risk indicators of work-related over-exertion back injuries among nursing personnel. In: Hagberg, M., Hofmann, F., Stossel, U., Westlander, G., (Eds.), Occupational Health for Health Care Workers. First update 7/95, Ecomed, Landsberg, pp. 327-329..

Wiktorin, Ch., Karlqvist, L. and Winkel, J., 1993. Validity of self-reported exposures to work postures and manual materials handling. Scandinavian Journal of Work, Environment and Health 19, pp. 208-214.

Winkelmolen, G.H.M., Landeweerd, J.A. and Drost, M.R., 1994. An evaluation of patient lifting techniques. Ergonomics 37, pp. 921-932. 
Knibbe, J.J., Friele, R.D. The use of logs to assess exposure to manual handling of patients, illustrated in an intervention study in home care nursing. International Journal of Industrial Ergonomics: 1999, 24(4), 445-454

\section{TABLES}

Table 1

Average number of transfers per nurse/week and standard deviation (SD) pre and post intervention for the total group, the intervention and the control group. Significant differences between pre and post intervention are indicated

\begin{tabular}{|c|c|c|c|c|c|}
\hline \multirow{2}{*}{ Type of transfer activity } & \multicolumn{2}{|c|}{ Pre intervention } & \multicolumn{2}{|c|}{ Post intervention } & \multirow{2}{*}{$\begin{array}{l}\text { Differences ( } p \text {-value) } \\
\text { Pre-post intervention }\end{array}$} \\
\hline & Average & SD & Average & SD & \\
\hline Total group & $n=104$ & & $n=116$ & & \\
\hline 1. Bed $\langle-\rangle$ (wheel)chair & 4.06 & 3.88 & 3.22 & 3.99 & \\
\hline 2. Bed $\langle->$ toilet & 0.58 & 1.72 & 0.91 & 2.73 & \\
\hline 3. (Wheel)chair $\langle-\rangle$ (toilet)chr & 2.91 & 5.70 & 1.70 & 3.63 & ${ }^{\mathrm{a}} .0037$ \\
\hline 4. (Wheel)chair $\langle-\rangle$ toilet & 0.75 & 1.68 & 0.69 & 1.75 & \\
\hline 5. Bed transfers sec & 4.30 & 5.65 & 2.85 & 4.19 & \\
\hline 6. Bed transfers(care related) & 4.89 & 5.36 & 3.71 & 3.63 & \\
\hline 7. Showering standing & 2.82 & 3.75 & 2.67 & 3.57 & \\
\hline 8. Showering sitting & 5.90 & 5.00 & 5.74 & 5.11 & \\
\hline 9. In/out of bathtub & 0.39 & 1.11 & 0.38 & 0.86 & \\
\hline 10. Higher up in a chair & 2.01 & 4.43 & 0.75 & 1.77 & ${ }^{\mathrm{a}} .0054$ \\
\hline 11. Lifting from floor & 0.43 & 1.90 & 0.06 & 0.24 & \\
\hline Total & 29.05 & 19.54 & 22.69 & 14.56 & \\
\hline Intervention group & $n=50$ & & $n=51$ & & \\
\hline 1. Bed $\langle->$ wheel(chair) & 5.18 & 4.34 & 3.29 & 3.82 & \\
\hline 2. Bed $\langle->$ toilet & 0.96 & 2.34 & 1.02 & 3.66 & \\
\hline 3. (Wheel)chair $\langle-\rangle$ (toilet)chr & 4.16 & 7.52 & 1.12 & 2.92 & ${ }^{\mathrm{a}} .0015$ \\
\hline 4. (Wheel)chair $\langle->$ toilet & 1.26 & 2.23 & 0.63 & 1.80 & ${ }^{\mathrm{a}} .0253$ \\
\hline 5. Bed transfers sec & 6.20 & 6.72 & 3.25 & 4.81 & ${ }^{\text {a. }} .0494$ \\
\hline 6. Bed transfers(care related) & 6.00 & 5.71 & 4.25 & 3.86 & \\
\hline 7. Showering standing & 2.36 & 3.01 & 1.43 & 2.13 & \\
\hline 8. Showering sitting & 6.20 & 4.83 & 4.90 & 4.41 & ${ }^{\mathrm{a}} .0148$ \\
\hline 9. In/out of bathtub & 0.46 & 1.27 & 0.33 & 0.79 & \\
\hline 10. Higher up in a chair & 1.92 & 4.53 & 0.96 & 2.27 & \\
\hline 11. Lifting from floor & 0.32 & 1.61 & 0.06 & 0.24 & \\
\hline Total & 35.02 & 21.15 & 21.25 & 15.43 & ${ }^{\mathrm{a}} .0085$ \\
\hline Control group & $n=54$ & & $n=65$ & & \\
\hline 1. Bed $\langle-\rangle$ (wheel)chair & 3.02 & 3.09 & 3.17 & 4.15 & \\
\hline 2. Bed $\langle-\rangle$ toilet & 0.22 & 0.63 & 0.83 & 1.71 & \\
\hline 3. (Wheel)chair $\langle-\rangle$ (toilet)chr & 1.76 & 2.84 & 2.15 & 4.07 & \\
\hline 4. (Wheel)chair $\langle-\rangle$ toilet & 0.28 & 0.63 & 0.74 & 1.73 & \\
\hline 5. Bed transfers sec & 2.54 & 3.70 & 2.54 & 3.64 & \\
\hline 6. Bed transfers (care related) & 3.87 & 4.86 & 3.28 & 3.42 & \\
\hline 7. Showering standing & 3.24 & 4.31 & 3.65 & 4.15 & \\
\hline 8. Showering sitting & 5.63 & 5.18 & 6.40 & 5.53 & \\
\hline 9. In/out of bathtub & 0.33 & 0.95 & 0.42 & 0.92 & \\
\hline 10. Higher up in a chair & 2.09 & 4.37 & 0.58 & 1.25 & ${ }^{\mathrm{a}} .0006$ \\
\hline 11. Lifting from floor & 0.54 & 2.15 & 0.06 & 0.24 & \\
\hline Total & 23.52 & 16.22 & 23.82 & 13.86 & \\
\hline
\end{tabular}

${ }^{a}$ Significance between pre/post intervention: Wilcoxon $p<0.05$. 
Table 2

Average total number of transfers (per nurse /week), average number of transfers for which hoists can be used (hoist potential), average number of transfers that cannot be solved with hoists (non-hoist transfers) and the average frequency of actual transfers performed with a hoist (and percentage of this frequency of the hoist potential frequency) for intervention and control group, pre- and postintervention (see text)

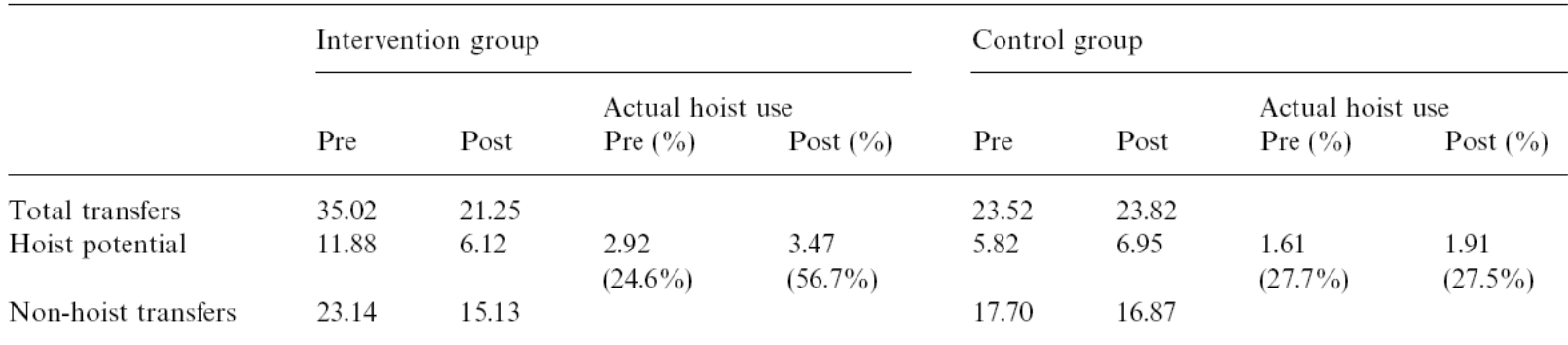

